University of Nebraska - Lincoln

DigitalCommons@University of Nebraska - Lincoln

Extending the soil moisture data record of the U.S. Climate Reference Network (USCRN) and Soil Climate Analysis Network (SCAN)

\author{
Ethan J. Coopersmith \\ USDA-ARS Hydrology and Remote Sensing Laboratory \\ Jesse E. Bell \\ North Carolina Institute for Climate Studies (NCICS), North Carolina State University \\ Michael H. Cosh \\ USDA-ARS Hydrology and Remote Sensing Laboratory
}

Follow this and additional works at: https://digitalcommons.unl.edu/usdaarsfacpub

Part of the Environmental Monitoring Commons

\begin{abstract}
Coopersmith, Ethan J.; Bell, Jesse E.; and Cosh, Michael H., "Extending the soil moisture data record of the U.S. Climate Reference Network (USCRN) and Soil Climate Analysis Network (SCAN)" (2015).

Publications from USDA-ARS / UNL Faculty. 1499.

https://digitalcommons.unl.edu/usdaarsfacpub/1499
\end{abstract}

This Article is brought to you for free and open access by the U.S. Department of Agriculture: Agricultural Research Service, Lincoln, Nebraska at DigitalCommons@University of Nebraska - Lincoln. It has been accepted for inclusion in Publications from USDA-ARS / UNL Faculty by an authorized administrator of DigitalCommons@University of Nebraska - Lincoln. 


\title{
Extending the soil moisture data record of the U.S. Climate Reference Network (USCRN) and Soil Climate Analysis Network (SCAN)
}

\author{
Evan J. Coopersmith ${ }^{\mathrm{a}, *}$, Jesse E. Bell ${ }^{\mathrm{b}}$, Michael H. Cosh ${ }^{\mathrm{a}}$ \\ ${ }^{a}$ USDA-ARS Hydrology and Remote Sensing Laboratory, Beltsville, MD, United States \\ ${ }^{\mathrm{b}}$ North Carolina Institute for Climate Studies (NCICS), North Carolina State University, 151 Patton Avenue, Asheville, NC 28801, United States
}

\section{A R T I C L E I N F O}

\section{Article history:}

Received 7 November 2014

Received in revised form 9 February 2015

Accepted 9 February 2015

Available online 25 February 2015

\section{Keywords:}

Soil moisture

Climate Reference Network

Hydrologic modeling

Genetic algorithms

Soil Climate Analysis Network

\begin{abstract}
A B S T R A C T
Soil moisture estimates are valuable for hydrologic modeling, drought prediction and management, climate change analysis, and agricultural decision support. However, in situ measurements of soil moisture have only become available within the past few decades with additional sensors being installed each year. Comparing newer in situ resources with older resources, previously required a period of crosscalibration, often requiring several years of data collection. One new technique to improve this issue is to develop a methodology to extend the in situ record backwards in time using a soil moisture model and ancillary available data sets. This study will extend the soil moisture record of the U.S. Climate Reference Network (USCRN) by calibrating a precipitation-driven model during the most recent few years when soil moisture data are available and applying that model backwards temporally in years where precipitation data are available and soil moisture data are not. This approach is validated by applying the technique to the Soil Climate Analysis Network (SCAN) where the same model is calibrated in recent years and validated during preceding years at locations with a sufficiently long soil moisture record. Results suggest that if two or three years of concurrent precipitation and soil moisture time series data are available, the calibrated model's parameters can be applied historically to produce RMSE values less than $0.033 \mathrm{~m}^{3} / \mathrm{m}^{3}$. With this approach, in locations characterized by in situ sensors with short or intermittent data records, a model can now be used to fill the relevant gaps and improve the historical record as well.
\end{abstract}

Published by Elsevier Ltd.

\section{Introduction}

Long-term soil moisture estimates play an integral role in hydrological modeling by providing data to estimate subsurface flows at the watershed scale (e.g. [16]). In agriculture, estimates of soil moisture facilitate real-time irrigation scheduling [22] as well as assessments of the field's potential trafficability $[6,11,26]$. Simulations of soil moisture are pivotal in predictions and analyses of historical drought, (e.g. [26]) important to the study of climate change, and remain a source of uncertainty for some General Circulation Models (GCM) (e.g. [4,17]).

Currently, in situ soil moisture estimates are available from United States, state-level climatic networks in Illinois, Oklahoma, North Carolina, Nebraska, and Texas, providing daily or hourly estimates at numerous locations throughout the state, though without consistent measurement standards [20]. Similar hourly soil moisture estimates are available throughout the United States via the Soil Climate Analysis Network (SCAN) [24]. These sensor

\footnotetext{
* Corresponding author.
}

installations, at 100+ sites distributed nationally over forty states, began as early as 2000 . While some of these sites have gaps in their data records, others provide a lengthier record from which to perform more substantial analyses. In contrast, the U.S. Climate Reference Network (USCRN), contains 114 sites nationwide, characterized by far fewer data gaps [8]. However, these soil moisture data begin only in 2009 , while co-located precipitation gages have been reporting since 2002, and in some cases, for decades prior [1]. Fig. 1 presents a map of SCAN and USCRN locations throughout the continental United States. USCRN sites are distributed uniformly throughout the U.S., while SCAN is characterized by certain areas with increased density, usually to accommodate specific research studies.

Previous research has typically attempted to address the limitations of the existing sources of soil moisture data by extrapolating spatially (e.g. [27]). This has been achieved by applying the parameters of soil moisture models calibrated by in situ instruments with co-located precipitation gauges to hydro-climatically and edaphically similar locations that lack such sensors [7] or by interpolating between the sensors of sparse networks maintained by the 


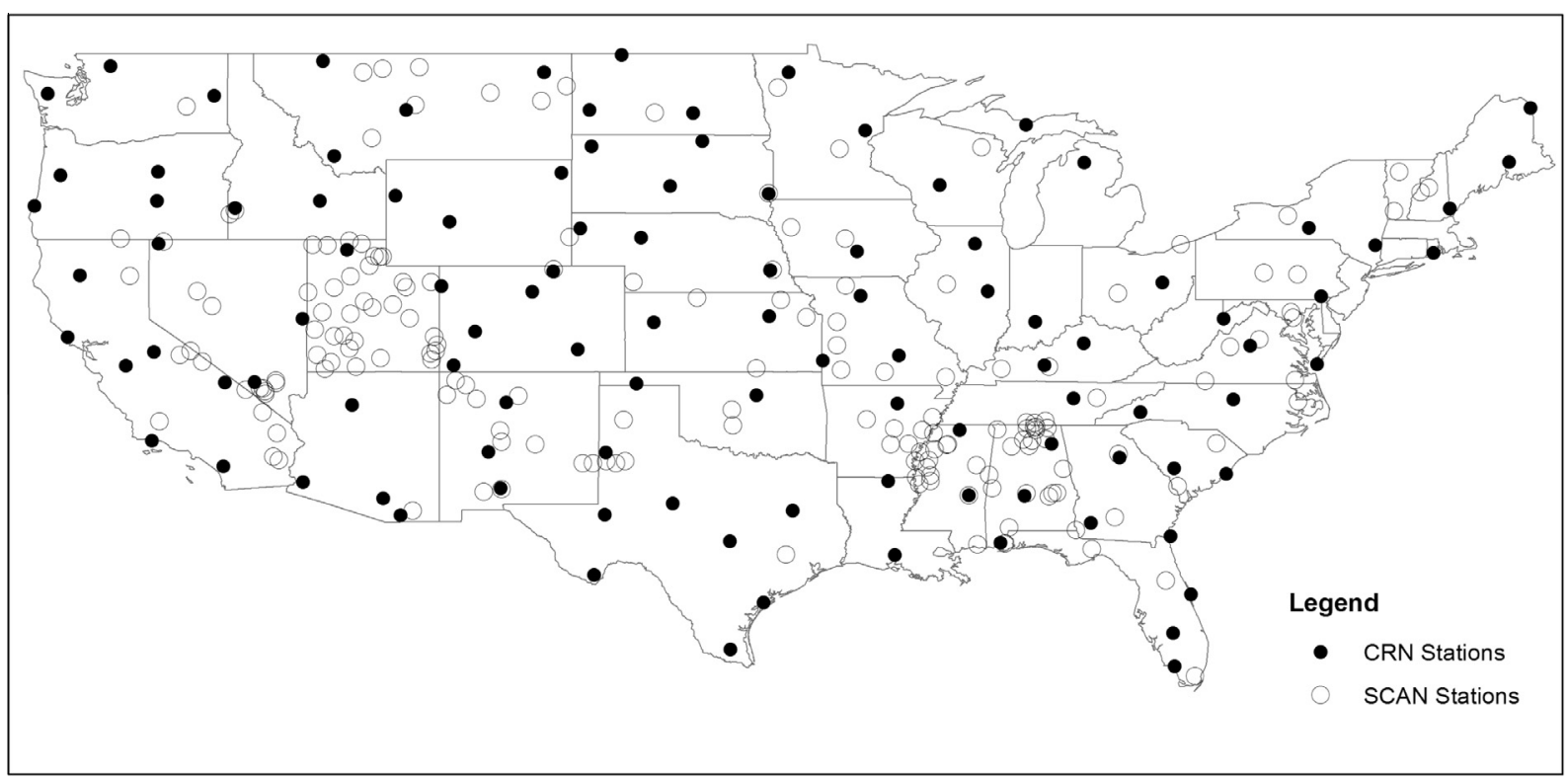

Fig. 1. NOAA Climate Reference Network (CRN) and USDA Soil Climate Analysis Network locations in the contiguous U.S.

Agricultural Research Service (ARS) and assimilating remotelysensed precipitation data [5]. Stillman et al. [27] attempted to extend the spatial scope of an in situ soil moisture network in Arizona using a dense network of precipitation gauges and then subsequently to extend those estimates back historically. However, little has been done to extend the soil moisture record historically on a broader, continental scale.

To achieve a historical extension of the soil moisture record, certain features are required for model selection. Firstly, antecedent soil moisture conditions cannot be required, as these, by definition, would be unavailable if we intend to predict backwards in time. Though precipitation variability is generally accepted to be the primary driver of wetting and drying [12], the antecedent precipitation index (API) approach used to estimate soil moisture [23] or even the stochastic tool designed to estimate soil moisture distributions [14], necessitate an initial condition at the model's location. Even if a soil water balance approach were deployed with the intention of remedying this issue, one would need to generate an initial soil moisture condition at the beginning of the time period historically for which the record is to be extended and then incur cumulative errors for the duration of the extension period [18]. As the period over which we aspire to extend the soil moisture record could be years or even decades, the cumulative errors must be accounted for and reduced.

To this end, the diagnostic soil moisture equation, introduced by Pan et al. [20] and subsequently updated by Pan [21] was most suitable to perform this analysis. A parsimonious, lumped-bucket model does not require any specification of an initial condition for soil moisture and need not receive periodic recalibrations. By transforming a precipitation time series into a soil moisture time series via an exponentially decaying convolution, all that is required to generate a soil moisture estimate at any given time is a precipitation time series preceding the time for which an estimate is desired and the calibrated parameters (constants used as inputs for the equation itself). Precipitation data are widely available while soil moisture data are not. It is in this vein that this work can benefit future research. It is worth noting that precipitation and soil moisture are not independent variables in studying past conditions if the soil moisture data are derived from the precipitation data - this must be acknowledged if the extended soil moisture record is deployed for subsequent analysis. Though the original research calibrated the diagnostic soil moisture equation as a daily model, our approach outfits the model as an hourly estimator, using genetic algorithms for calibration [7] rather than the Monte Carlo approach favored by Pan [21]. By calibrating the diagnostic soil moisture equation and validating those algorithms during previous years, this work demonstrates the feasibility of such an approach at USCRN stations, thereby extending the soil moisture record. The reverse of this procedure has been performed previously, generating a precipitation time series from soil moisture estimates [2] and extending these results into the past via a hydrologic model [3].

\section{Methodology}

The diagnostic soil moisture equation appears in Eq. (1)below:

$\theta_{\text {est }}=\theta_{r e}+\left(\phi_{e}-\theta_{r e}\right)\left(1-e^{-c_{4} \beta}\right)$

During any given hour, $\theta_{\text {est }}$ represents the model's estimate of soil moisture. Residual soil moisture, the minimum quantity of moisture that remains indefinitely, even without precipitation, is denoted by $\theta_{\text {re }}$. The soil's porosity, the maximum possible soil moisture value, at which point the soil becomes saturated, is defined by $\phi_{e}$. Finally conductivity and drainage properties, quantifying the rate at which soil can dry, is signified by the parameter, $c_{4}$. If $c_{4}$ becomes large, the soil's drying rate approaches zero, that is, it remains saturated at its porosity, $\phi_{e}$. If $c_{4}$ assumes a value of zero, the soil dries instantaneously, that is, it remains at the residual soil moisture, $\theta_{\text {re }}$. Eq. (2) below presents the $\beta$ series.

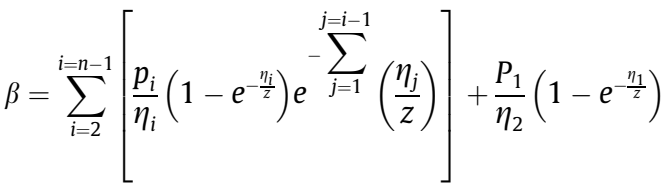

In Eq. (2), the quantity of rainfall during hour $i$ is represented by $P_{i}$, the soil depth is defined by $z$, and $n$ denotes the number of hours for which we must consider antecedent precipitation. Modeling today's soil moisture requires knowledge of yesterday's rainfall, but does not require the rainfall from the previous two years. For the purposes of this analysis, at SCAN and USCRN sites, the $5-\mathrm{cm}$ measurement will be used. Finally, $\eta_{i}$ denotes the estimated soil 
water loss at hour $i$ due to deep drainage or other evapotranspirative losses, assumed to be a sinusoid with a period of one year, shown in Eq. (3).

$\eta=\alpha \sin (i-\delta)+\gamma$

The sinusoid's amplitude, vertical shift, and phase shift are denoted by $\alpha, \gamma$, and $\delta$ respectively. These three parameters are fit via a real-coded genetic algorithm containing selection, crossover, and mutation (see [15] such that correlation between the $\beta$-series and $\theta_{\text {est }}$ is maximized. The sinusoidal curve produces strong results with respect to soil moisture model calibrations throughout the United States where temperatures increase in the summer, vegetation grows, and ET increases. The only location in the United States where the relationship is potentially non-sinusoidal is the southwest - where the model's results are actually the strongest. In turn, $\theta_{r e}, \phi_{e}$, and $c_{4}$ are fit via a second genetic algorithm to minimize the root-mean-squared-error (RMSE) between $\theta_{\text {est }}$ and the empirical, in situ measurements of soil moisture.

Using this approach, any site can be calibrated if a sufficiently lengthy time series of precipitation and soil moisture are available. This time length is selected by calculating a $\beta$ series (Eq. (2)) where $n$ is very large, then generating a second $\beta$ series with a much smaller value for $n$ and increasing $n$ until the correlation between the two $\beta$ series generated approaches unity. In all cases, to avoid erroneous readings and subsequent mis-calibrations due to flooded sensors, any time stamps during which rain occurs are removed from the analysis, along with the four hours thereafter. Each calibration is evaluated in terms of the Pearson's $\rho$ correlation between soil moisture estimates and in situ measurements and in terms of the RMSE values obtained from comparing the estimated and measured soil moisture time series. While runoff is a common component of various water balance models, it is typically measured at the single point of outflow where as soil moisture is a point estimate at numerous in situ gauges within a watershed, each with a different residence time for moisture [10]. For this reason, with aims at maintaining parsimony of model structure, runoff is not included.

Prior to beginning a formal calibration/validation analysis of the SCAN network sites, it is important to ascertain which of these sites are viable candidates for such an analysis. While automated algorithms can note omitted data, when these values are erroneous, the process becomes far more complex. While a soil moisture value of $0.9 \mathrm{~m}^{3} / \mathrm{m}^{3}$ is almost certainly in error, as virtually no soil is sufficiently porous to yield such a reading, a precipitation value of $0 \mathrm{~mm}$ occurs both when no rain is occurring (common) and when a sensor fails to perceive rainfall that is legitimately occurring. To determine which years of SCAN data are acceptable for calibration/validation purposes, the diagnostic soil moisture equation was calibrated on each individual year of data at each of the 160 SCAN sites. At this stage, no validation occurred, as the primary goal is simply to determine if the diagnostic soil moisture equation can be calibrated adequately on each year for which data are available since 2000 . As only one-year periods are used for calibration, higher correlations and lower RMSE values are expected, especially as the obtained results are purely in-sample.

SCAN sites for which four or more consecutive years' calibrations during the growing season (April-October) were characterized by RMSE values below $0.04 \mathrm{~m}^{3} / \mathrm{m}^{3}$ (the target for average RMSE values achieved by NASA's current Soil Moisture Active Passive mission [13]), 64 in total, are reserved for further analysis ${ }^{1}$. These sites spanned 31 of SCAN's 40 states as well as Puerto Rico.

\footnotetext{
${ }^{1}$ Note, of the 96 sites eliminated, $\sim 50$ were eliminated due to the absence of four consecutive years of data, regardless of the quality of those data. The remaining sites were eliminated due to years in which even a single-year, completely in-sample calibration could not be calibrated to the $0.04 \mathrm{~m}^{3} / \mathrm{m}^{3}$ standard.
}

Moving forward with these 64 sites, first, models were calibrated during the most recent year of SCAN data, then validated on all preceding years. Next, models were calibrated during the most recent two-year period, then validated on all preceding years. Finally, models were calibrated during the most recent three-year period, then validated on all preceding years (the four-year minimum requirement ensures that after the three-year calibration, at least one year remains for validation). Having calibrated/validated three times per site, we eliminate all sites for which an RMSE value below $0.06 \mathrm{~m}^{3} / \mathrm{m}^{3}$ could not be achieved in validation (in validation, if $0.04 \mathrm{~m}^{3} / \mathrm{m}^{3}$ is to be achieved as an average RMSE, some values will exceed 0.04 and a $50 \%$ buffer seems appropriate), even after using three full years to calibrate. A total of 53 sites, spanning 27 states and Puerto Rico remained after this final cutoff. Generally, eliminated sites failed due to historical events that fell well outside the range of conditions experienced during calibration. If 53 of 64 sites perform well in validation (in terms of RMSE) after three or fewer years of calibration, then empirically, the range captured in calibration is likely sufficient. Liu et al. [19] assessed the quality of SCAN sites as well. Though our chosen subset overlaps substantially with their chosen SCAN sites, our sites were chosen independently, using both the prevalence of blacked-out data points (as Liu et al. had done) and the inability to calibrate a model (which they had not).

USCRN calibrations occurred in a manner analogous to the approach described for the SCAN network. Once again, precipitation events and the four hours thereafter were removed from the calibration and validation processes. In this case, models were calibrated from the sensor's initial installation, typically in 2009 or 2010 until the end of the 2012-growing season and validated during the growing season of 2013. Of the USCRN's 114 sensors, covering 42 states, sensors for which the RMSE values during validation exceed $0.06 \mathrm{~m}^{3} / \mathrm{m}^{3}$ are removed from the analysis, leaving 91 USCRN sites, over 38 states, that are candidates to be extended backwards historically. Additional analysis regarding the quality of SCAN and USCRN sensors can be found in Dorigo et al. [9] and Bell et al. [1]. Additional information regarding the sites our analysis has excluded can be found in an Appendix A.

Finally, these historical extensions of the soil moisture data record using the models calibrated at these USCRN sites are analyzed to determine if the distribution of modeled soil moisture estimates appears similar to the distribution of in situ measurements obtained at the same location.

\section{Results}

\subsection{SCAN results}

With a single-year to calibrate, the average correlation coefficient during calibration $(\rho=0.883)$ and RMSE value $\left(0.0208 \mathrm{~m}^{3} / \mathrm{m}^{3}\right)$ are strong, yielding correlation and RMSE values of 0.780 and $0.0387 \mathrm{~m}^{3} / \mathrm{m}^{3}$ during the remaining validation period, see Figs. 2 and 3.

Continuing, a second year is added to the calibration period. With the addition of the second year (see Figs. 2 and 3), performance declines during calibration $\left(\rho=0.868, \quad\right.$ RMSE $\left.=0.0232 \mathrm{~m}^{3} / \mathrm{m}^{3}\right)$. However, as expected, a more robust calibration period improves the average performance in validation historically $(\rho=0.812$, RMSE $=0.0345 \mathrm{~m}^{3} / \mathrm{m}^{3}$ ) as compared to the results following only a single year of calibration.

Finally, by adding the third year of calibration (see Figs. 2 and 3 ), the results are essentially identical with respect to in-sample performance $\left(\rho=0.874, \quad \operatorname{RMSE}=0.0238 \mathrm{~m}^{3} / \mathrm{m}^{3}\right)$. This is an increase of 0.006 with respect to correlation and an increase of $0.0006 \mathrm{~m}^{3} / \mathrm{m}^{3}$ with respect to RMSE. However, while the in-sample calibrations are comparable, the validation results historically are 


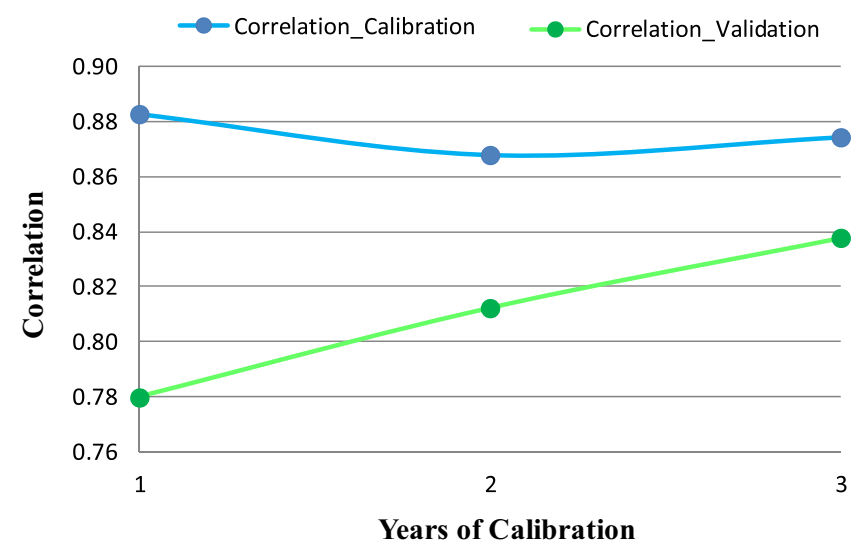

Fig. 2. Average correlation over all sites with additional years of calibration.

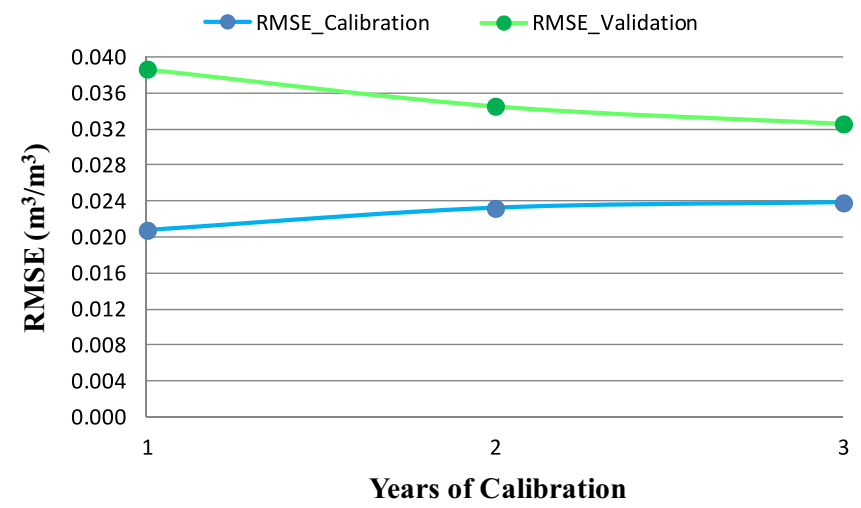

Fig. 3. Average RMSE over all sites with additional years of calibration.

improved by the more robust calibration data set provided by the third year, improving upon the validation results historically $\left(\rho=0.838\right.$, RMSE $\left.=0.0326 \mathrm{~m}^{3} / \mathrm{m}^{3}\right)$.

Fig. 4 illustrates the relationship between RMSE values during the calibration and validation processes using one, two, or three years of calibration. In these cases, we observe that with each additional year, the scatterplot nears the line with a slope of unity. It is likewise the case that a handful of sites never achieve a sufficient calibration (RMSE $<0.06 \mathrm{~m}^{3} / \mathrm{m}^{3}$ ) even after three years of calibration, justifying their elimination. Typically, these eliminated sites contain sensors that either fail to respond to rain events, remain flooded for protracted periods, or experience such quantities of missing data that successful calibration is simply not possible.
These results suggest that by adding a second and third year of calibration data, historical predictions can perform quite well. Furthermore, the quality of performance is not a function of the length of the historical periods, as for many of these SCAN sites, calibration occurs during the growing season of 2011, 2012, and 2013, with validation occurring during the period preceding 2011's growing season, reaching back to 2004 or 2005, and in some cases, as far back as 2002 .

\subsection{USCRN results}

For the 114 USCRN installations, 91 sites have sufficient data records for this calibration/validation procedure, using the same requirement of a validation RMSE less than $0.06 \mathrm{~m}^{3} / \mathrm{m}^{3}$. Calibrations occurred between the sensor's installation during 2009 or 2010 and the end of the 2012 growing season. In Fig. 3, we observe that the average correlation and RMSE values in-sample $\left(\rho=0.892\right.$, RMSE $\left.=0.0256 \mathrm{~m}^{3} / \mathrm{m}^{3}\right)$ are comparable to the performance observed using two or three years of calibration data at SCAN sites (Figs. 1 and 2) of $\rho=0.874$, RMSE $=0.0238 \mathrm{~m}^{3} / \mathrm{m}^{3}$, respectively. During validation during the growing season of 2013, the correlation and RMSE values $(\rho=0.824$, RMSE $=$ $0.0320 \mathrm{~m}^{3} / \mathrm{m}^{3}$ ) are similar to the analogous values obtained during validation at the SCAN sites after two or three years of calibration (Figs. 2 and 3) of $\rho=0.838$, RMSE $=0.0326 \mathrm{~m}^{3} / \mathrm{m}^{3}$ respectively.

Fig. 5, analogous to Fig. 4, presents the same relationship for the USCRN sites. Unlike Fig. 4, there are sites that produce a lower RMSE during validation than during calibration. In total however, a very similar relationship is achieved, that is, a scatterplot slightly above the line with a slope of unity. Also similar, there are a handful of sites for which successful calibrations are not possible and are excluded from the average values presented. It is therefore reasonable to presume comparable strength of calibrations at these 93 'best' USCRN sites and the 64 'best' SCAN locations.

\subsection{Historical results}

At each of the 55 well-calibrated SCAN sites, cumulative distribution functions (CDFs) were produced for three time series. The first was the in situ data gathered during the three-year calibration period. The second was the in situ data gathered during the validation period, preceding the calibration years, a period between one and six years in length. The third and final tine series was the model's estimate of soil moisture during the validation period. Fig. 6 presents nine such CDFs, presenting the in situ data during calibration (red lines) and validation (green dotted-lines) along with the modeled estimates during validation (blue dashed-lines). The images are arranged pseudo-geographically,
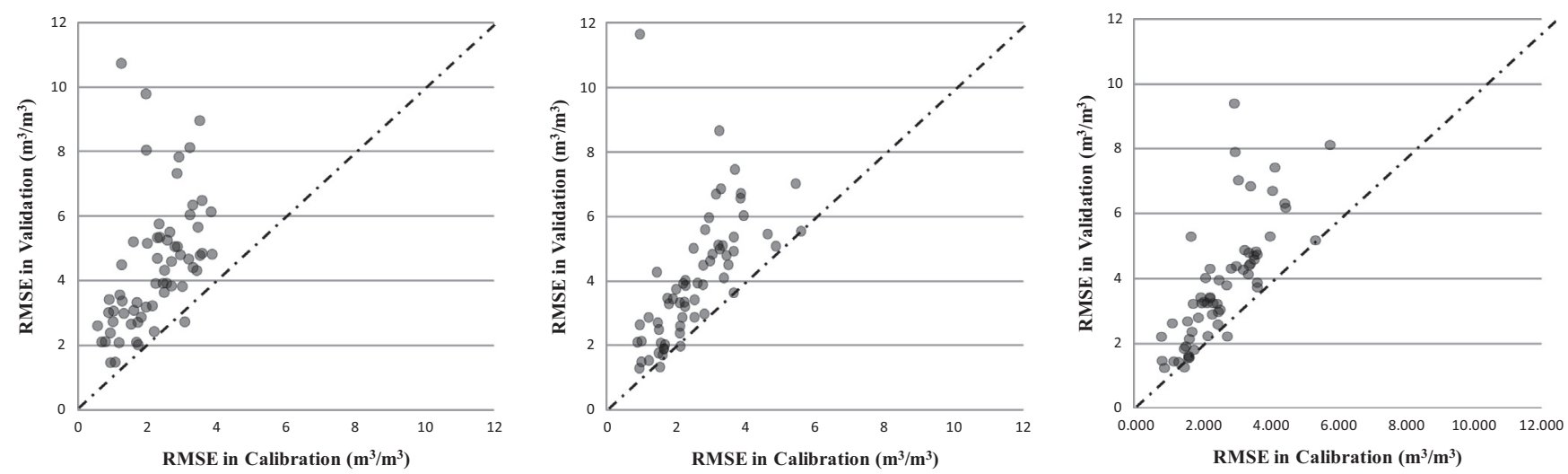

Fig. 4. SCAN sites, RMSE values in calibration and validation for single-year calibration (left), two-year calibration (center), and three-year calibration (right). 


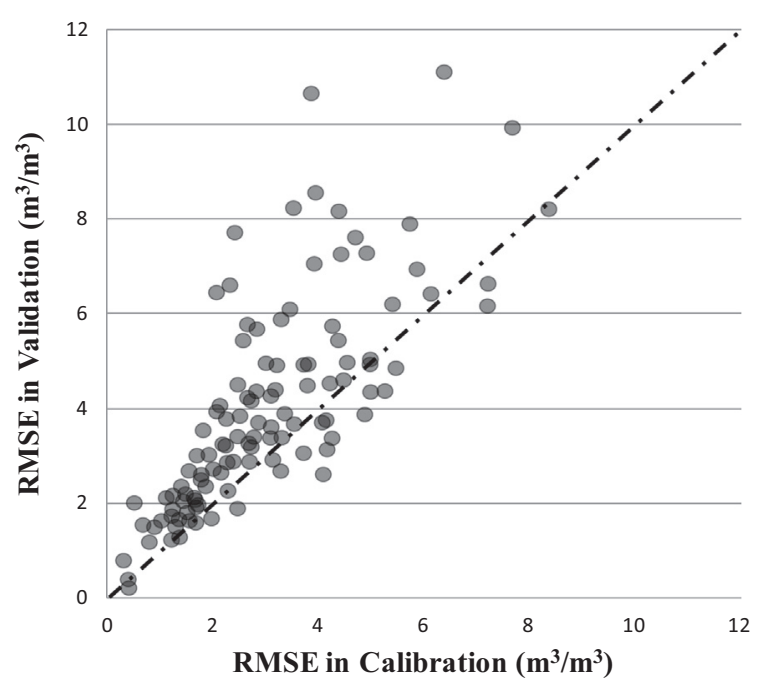

Fig. 5. USCRN RMSE values in calibration and validation (2009-2013).

with the top row containing sites in Washington, Wyoming, and New Hampshire, the middle row containing sites in Utah, Colorado, and Virginia, and the bottom row containing sites Arizona, Alabama, and Puerto Rico.

Taken in total, Fig. 6 suggests we are able to reproduce the distribution of soil moisture conditions in a diversity of hydroclimates over a variety of narrower and wider ranges of soil moisture values. Especially encouraging are the results at SCAN \#2021 in Washington (upper-left), where the validation data in situ are distributed differently than the calibration in situ data, yet the model, presented with the precipitation data during validation, approximates that different distribution effectively. Presenting an additional challenge are the results at SCAN \#2017 in Colorado (center-middle). In this case, the simulated soil moisture does not quite reach values as low as those observed empirically. As the objective in the calibration of these models is RMSE minimization, these tools have not been constructed in the optimal manner for drought prediction. To wit, if a model were designed for droughts, predicting a soil moisture level of $0.03 \mathrm{~m}^{3} / \mathrm{m}^{3}$ when the true value was $0.02 \mathrm{~m}^{3} / \mathrm{m}^{3}$ would be a greater mathematical sin than predicting $0.30 \mathrm{~m}^{3} / \mathrm{m}^{3}$ when the true value was $0.35 \mathrm{~m}^{3} / \mathrm{m}^{3}$. The former case is an error in assessing the severity of drought conditions while the latter is an error in characterizing soils that are clearly wet. However, in minimizing RMSE, the latter error is deemed to be $5 \times$ more severe than the first. This could be corrected by future modeling efforts where, during calibration, an additional incentive can be applied to models creating smaller errors at the lower end of the distribution.

Fig. 7 presents analyses of the same nine sites presented in Fig. 6, presenting the CDFs of each year within the calibration and validation samples rather than aggregating them into a single distribution. In this case, we are able to observe the diversity of distributions this model is capable of reproducing at the same location, given a different annual precipitation pattern. These results
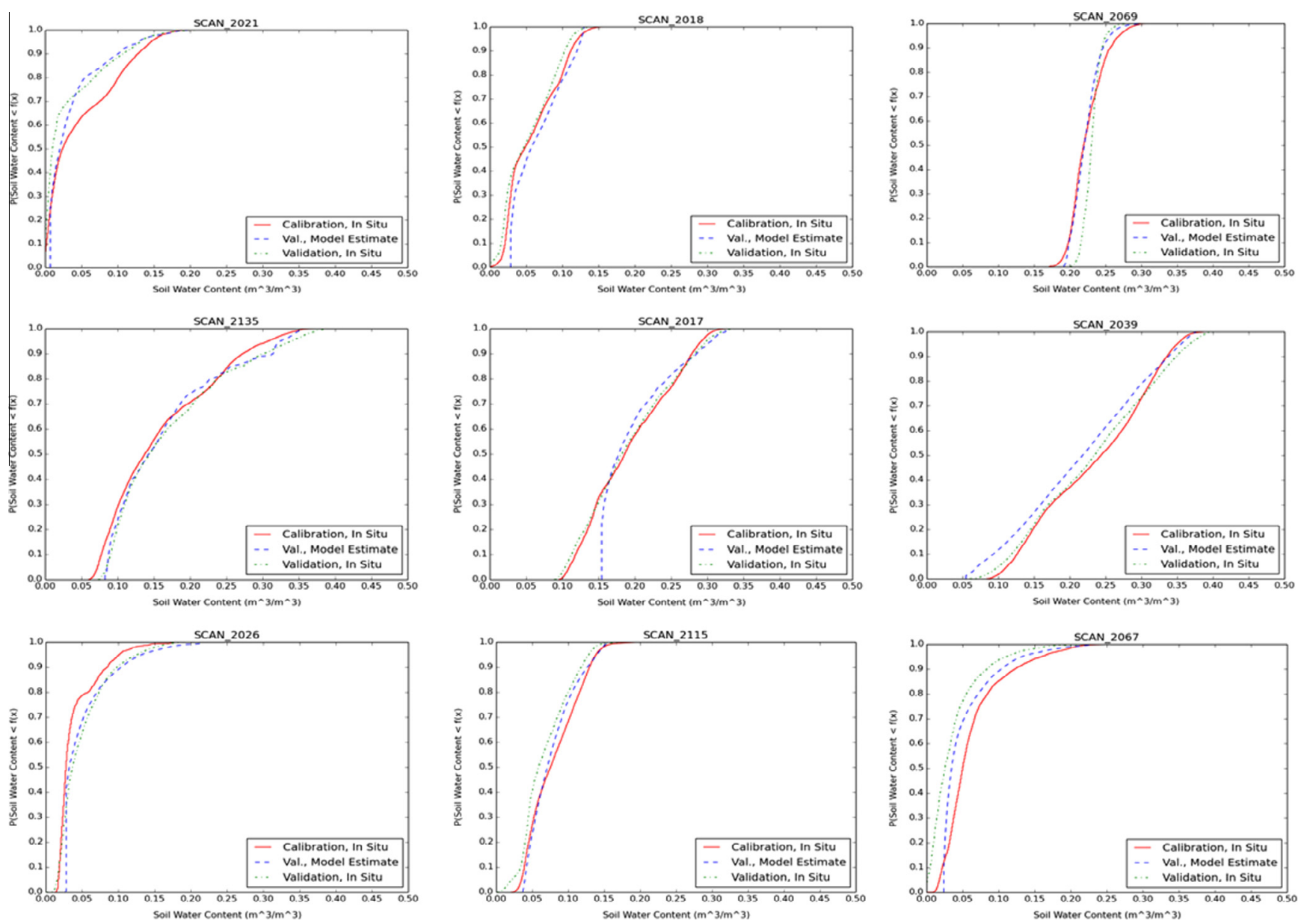

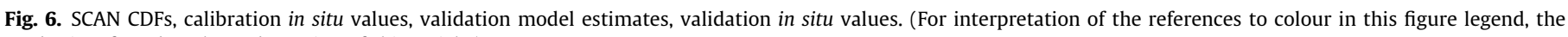
reader is referred to the web version of this article.) 

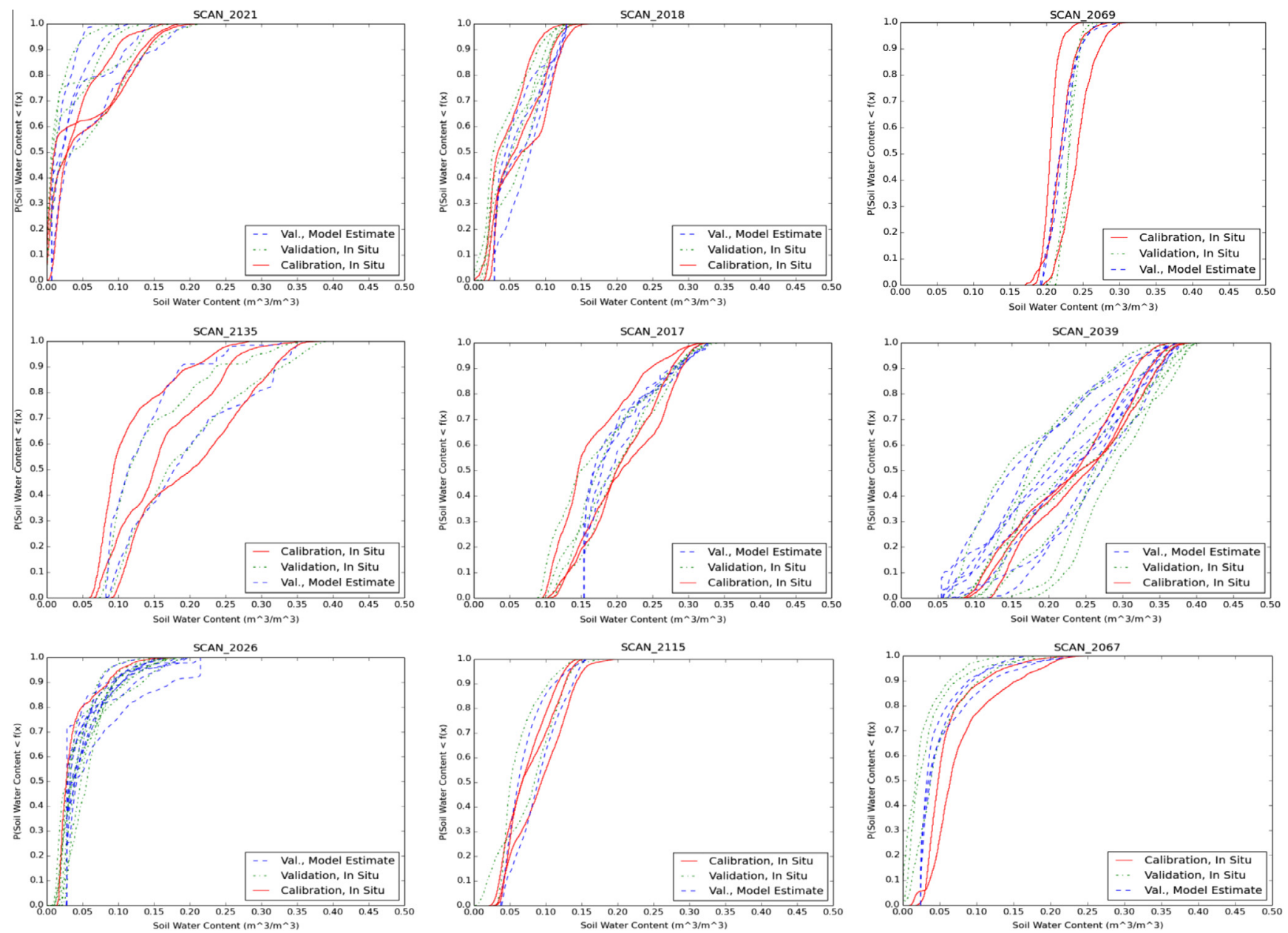

Fig. 7. SCAN annual CDFs, calibration in situ values, validation model estimates, validation in situ values.

are encouraging, demonstrating that the range of CDFs simulated seems largely indistinguishable from the range of CDFs generated from the in situ data measured empirically.

Fig. 8 presents the quantile-quantile plots at each of the nine sites chosen in Figs. 6 and 7. It is interesting to note that in most cases, the middle ranges of values display a linear relationship with a slope approaching unity. This would be consistent with the notion of a model's estimates approximately reproducing the distributions of in situ observations. However, in some cases, the ends of the distributions are truncated by the bounding parameters of the model, and as such, deviate from that linear relationship at the extremes. Given the elimination of rogue events from calibration as well as hours immediately following rain events, this is not surprising. With respect to Kolmogorov-Smirnov or other goodness-of-fit tests, these will show only if the modeled estimates and in situ observations differ in a matter that is statistically significant. Two distributions (especially those containing $\sim 40,000$ points in some cases) can be shown to be 'different', yet display remarkably similar character (hence the good qualitative fits shown in the Figs. 6 and 7). One would be hard-pressed to locate a multi-year, predicted time series with a high number of points that would not show a different distribution than the empirical observations, using a $\mathrm{K}-\mathrm{S}$ test.

Fig. 9 presents the calibration and validation results at two of these nine locations, on opposite ends of the continent, in Washington (top) and Virginia (bottom). In each chart, the in situ data are presented during calibration (red) and during validation (green) and the model's estimate is presented during both periods (blue). The upper chart, in Washington, demonstrates the model's capacity to trace the time series well during calibration and validation at a site where soil moisture values range from 0.00 to $0.20 \mathrm{~m}^{3} / \mathrm{m}^{3}$. The bottom chart presents a much more complicated and volatile soil moisture time series where values fall as low as $0.05 \mathrm{~m}^{3} / \mathrm{m}^{3}$ and reach above $0.40 \mathrm{~m}^{3} / \mathrm{m}^{3}$. In both cases, the calibration results are marginally better than those achieved during validation, demonstrating the efficacy of calibrating the diagnostic soil moisture equation, then applying its results backwards temporally.

For each of the 93 well-calibrated USCRN sites, historical soil moisture estimates were generated, using the parameters calibrated from installation to the end of the 2012-growing season. These estimates start at the availability of precipitation for each location (the year differs from site to site in the USCRN network) and end at the installation of the soil moisture sensors that subsequently provide empirical measurements. Fig. 10 presents the CDFs of the in situ measurements (red lines), overlaid with the CDFs of the modeled historical estimates (dashed-blue lines). Unlike Fig. 6, no green, dotted-line exists, as there are no historical soil moisture estimates prior to sensor installation in 2009 or 2010. The images are once again, arranged geographically, with the top line (from left-to-right) consisting of sites in Idaho, Michigan, and New Hampshire, the middle line presenting illustrations from California, Nebraska, and South Carolina, and the bottom line presenting images from Arizona, Texas, and Florida. In each of these nine examples, spanning the continent, a different cumulative distribution of in situ measurements is reproduced using the model and applied backwards historically. The results suggest that a diversity of soil moisture regimes can be emulated by these backwards 

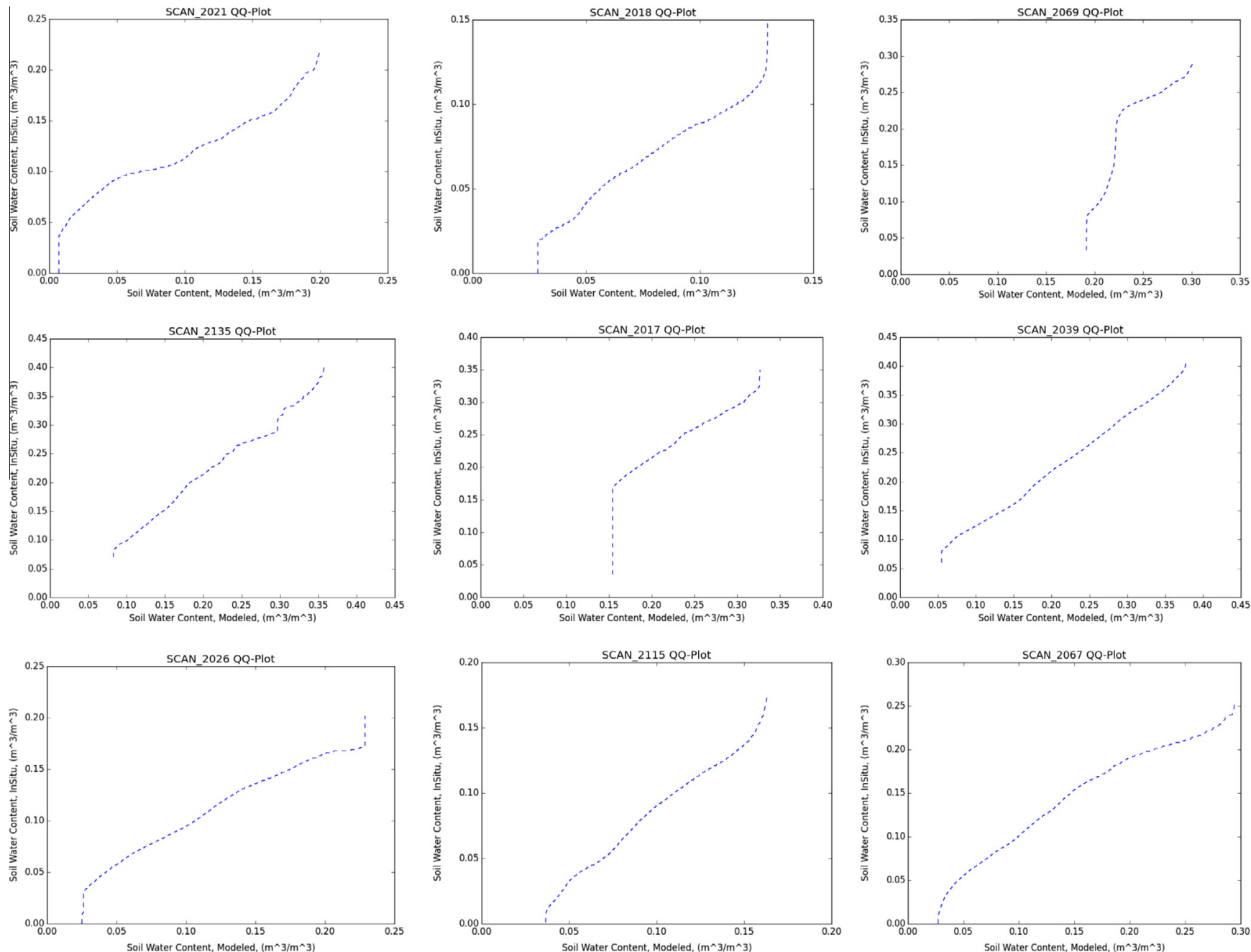

Fig. 8. SCAN QQ plots, validation in situ values vs. validation model estimates.
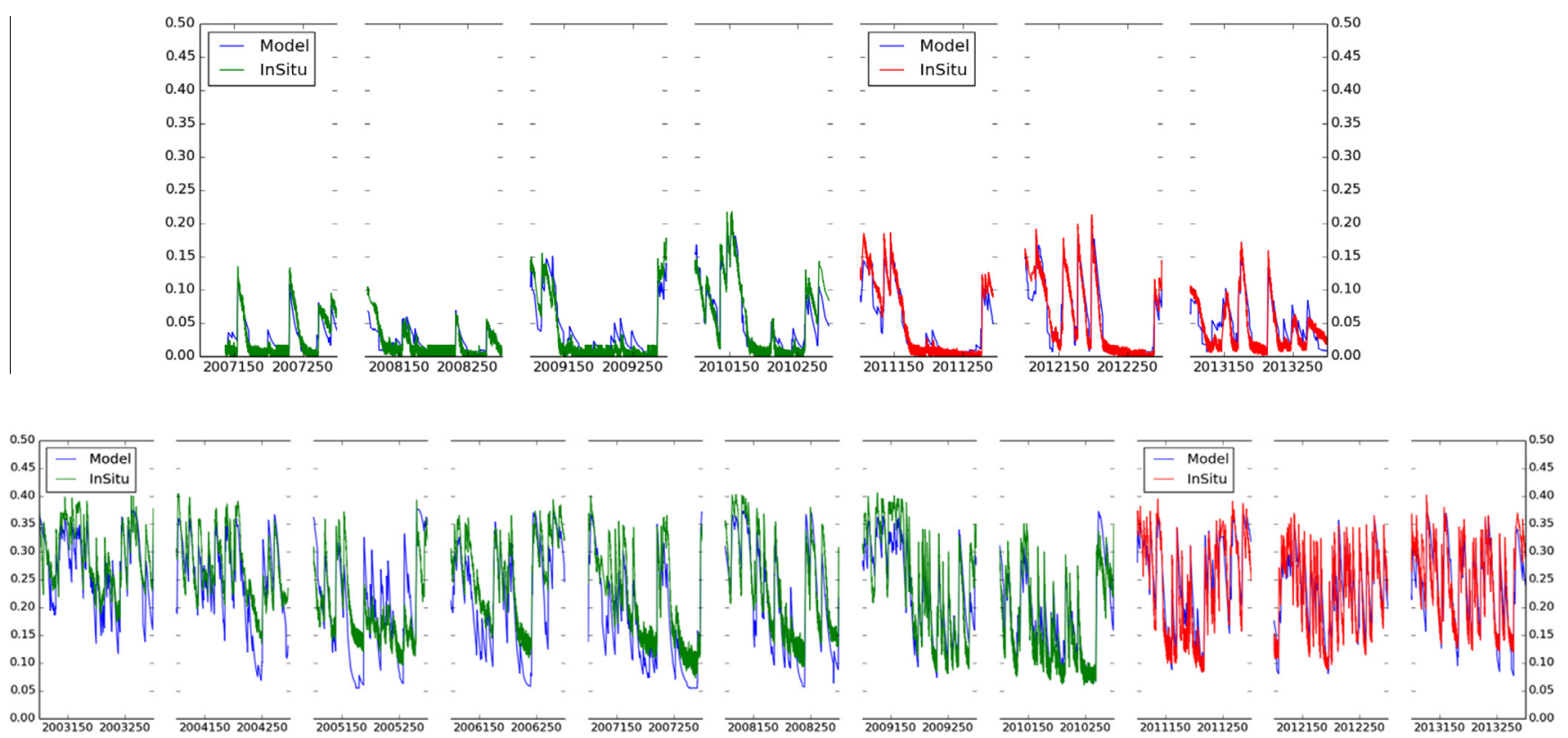

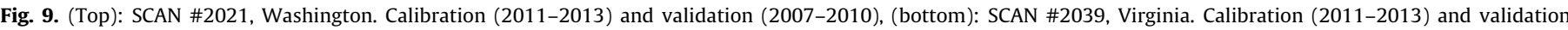
(2003-2010). 

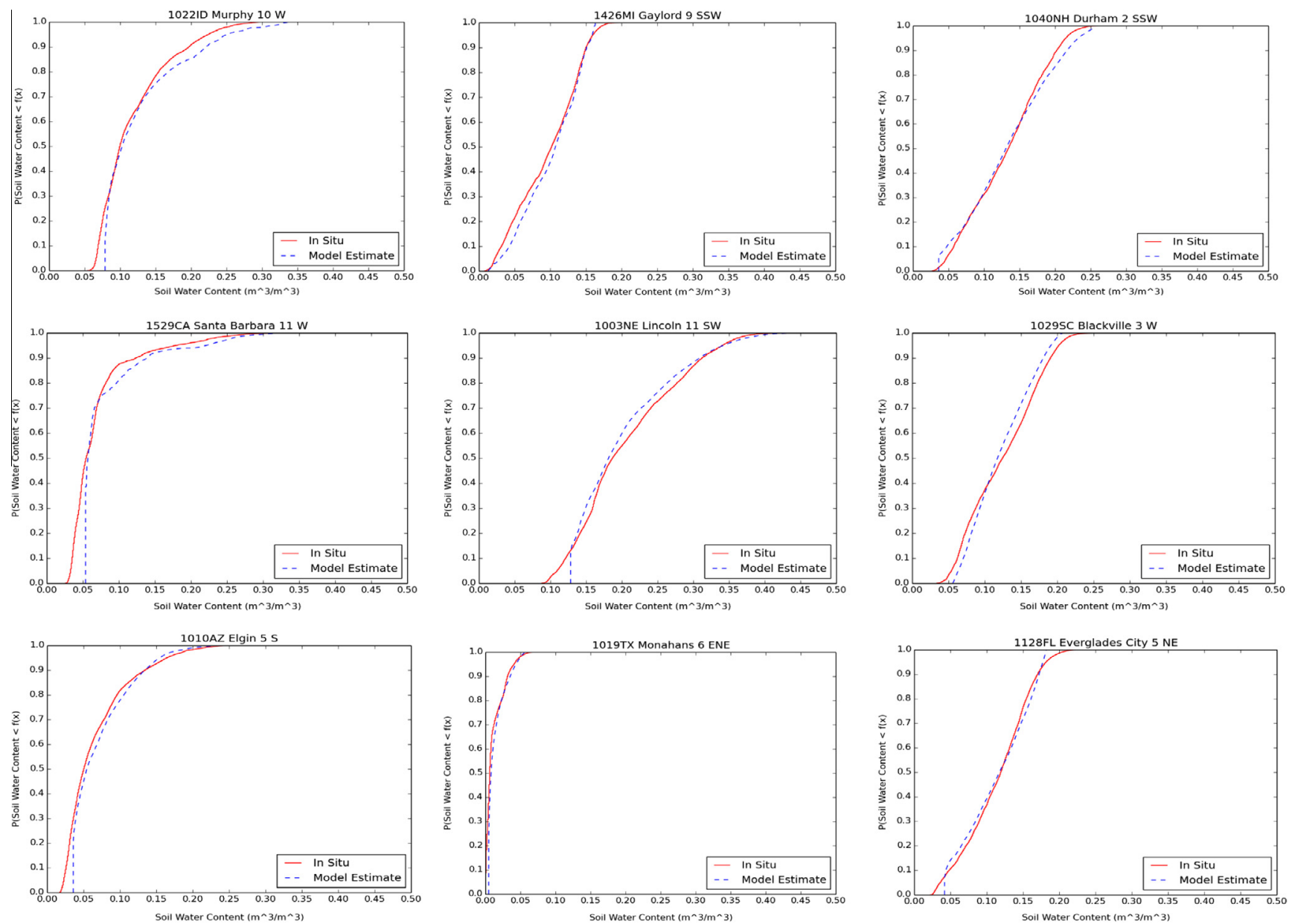

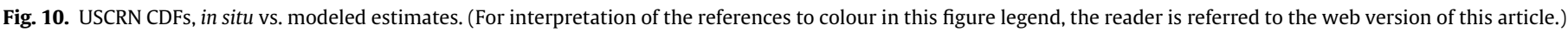

predictions. Fig. 11, like Fig. 7, presents the annual CDFs produced, illustrating that these USCRN sites' historical soil moisture model estimates resemble the distributions measured empirically.

Fig. 12, similar to Fig. 9, presents the time series at two USCRN sites, one in Nebraska (top) and another in Arizona (bottom). The Midwestern site presents a soil moisture range from more than $0.40 \mathrm{~m}^{3} / \mathrm{m}^{3}$ to less than $0.10 \mathrm{~m}^{3} / \mathrm{m}^{3}$ while the southwestern site ranges from 0.0 to $0.25 \mathrm{~m}^{3} / \mathrm{m}^{3}$. While it is the case that in situ data are unavailable prior to sensory installations in 2009, it is qualitatively true that the modeled soil moisture series strongly resembles the in situ time series, which the model does emulate well during calibration. It is this approach that will facilitate the extension of the soil moisture record at USCRN locations.

Fig. 13, like Fig. 1 presents an image of the United States, using color bars to illustrate the locations and efficacies of the calibration and validation of the models. In the case of USCRN sites, calibration occurs from 2009 through 2012, with validation occurring in 2013. In the case of SCAN sites (Fig. 14), validation occurs during years prior to calibration. Green reflects RMSE values below $0.05 \mathrm{~m}^{3} /$ $\mathrm{m}^{3}$, yellow reflects values between $0.05 \mathrm{~m}^{3} / \mathrm{m}^{3}$ and $0.06 \mathrm{~m}^{3} / \mathrm{m}^{3}$, and red reflects RMSE values above $0.06 \mathrm{~m}^{3} / \mathrm{m}^{3}$. Fig. 13 displays that this approach has been successful in dozens of states spanning the range of soil moisture values and hydroclimates presented across the United States, as well as in Hawaii and Puerto Rico. In the USCRN case, a site whose validation performance deteriorates somewhat presents a colorbar change from green to yellow moving left-to-right.

It is important to recognize that modeling past conditions with parameters that are static once calibrated does pose the issue of addressing non-stationary data (due to global warming or other sources). If these long-term climatic trends manifest in terms of differing precipitation patterns, then at least to some degree, the model accounts for the change. However, evaporative demand changes would not be addressed. This implies that, should the period of historical record grow to the scale of decades, the historical results could be useful to assess variability of soil moisture, but perhaps not the absolute values themselves.

\section{Conclusions}

Ultimately, these results suggest that a historical, modeled estimate can be comparable to in situ estimates in a variety of hydroclimates throughout the continental United States. This has been achieved first by calibrating soil moisture models at SCAN locations, then validating those models during previous years at those same locations where in situ measurements are available to evaluate the calibrated model. Next, having verified that soil moisture models can be calibrated and subsequently applied to previous years, models were calibrated at USCRN sites, verified to be robust calibrations by validating on a future year not used for calibration, then applied to previous years, during which precipitation estimates were available, but soil moisture estimates were not. By comparing the cumulative distribution functions of empirically-measured soil moisture with the historically modeled estimates, we have verified that the soil moisture values generated by the model are distributed similarly to those values empirically observed.

USCRN sites for which the historical record of precipitation is much longer than the soil moisture record become candidates for 

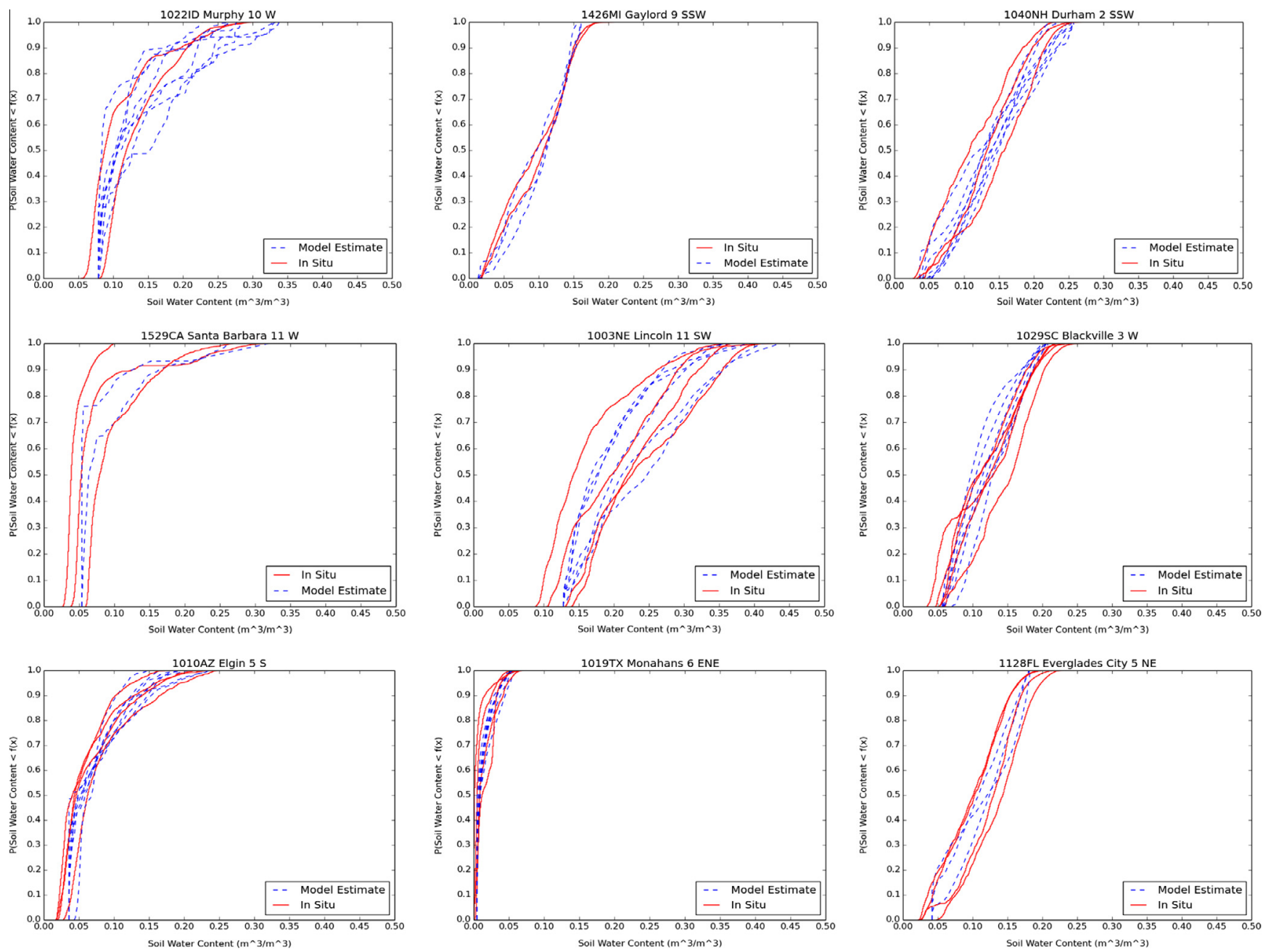

Fig. 11. USCRN annual CDFs, in situ vs. modeled estimates.

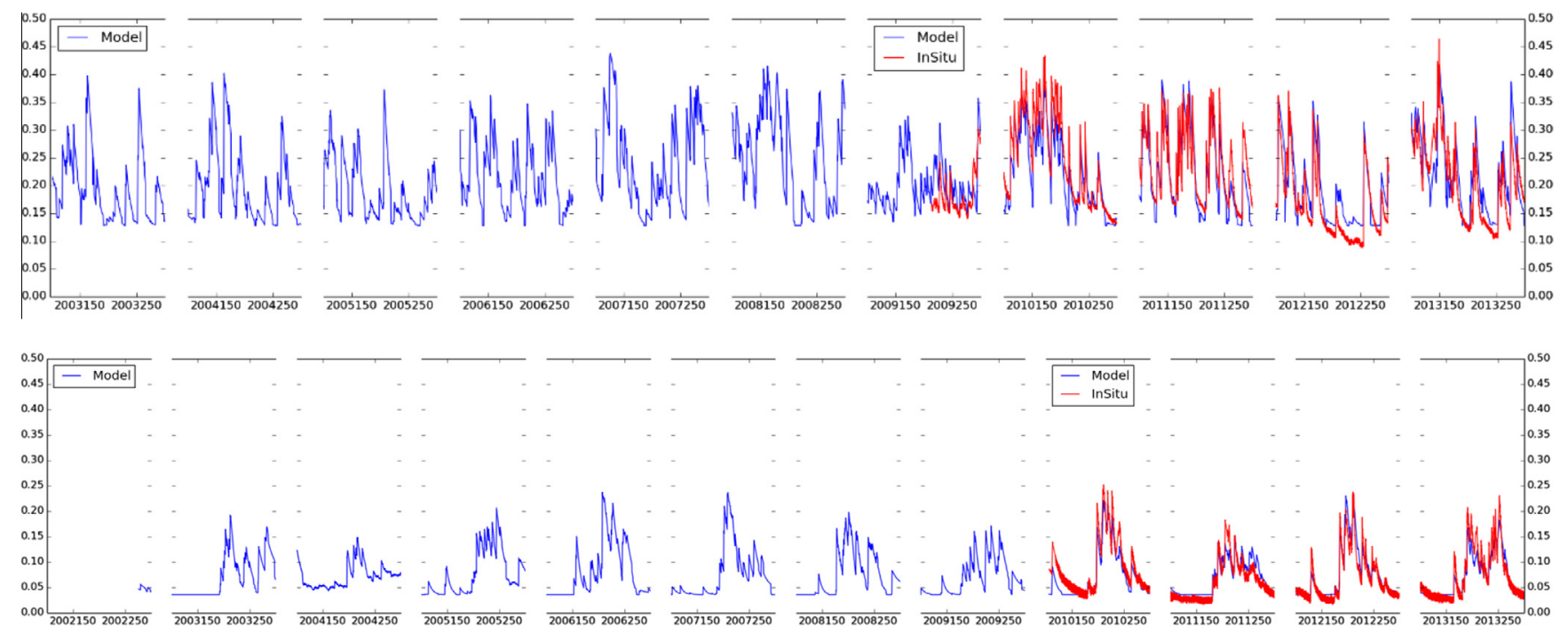

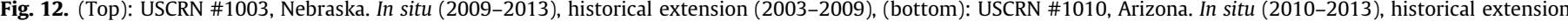
(2002-2009). 


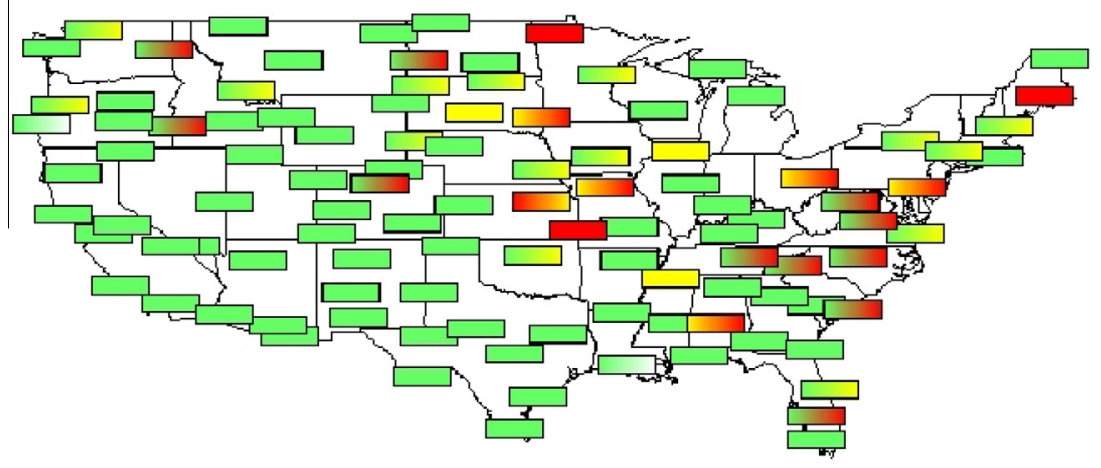

Fig. 13. USCRN calibration and validation results: left-end of bars reflect calibration performance, right-end reflects validation performance.

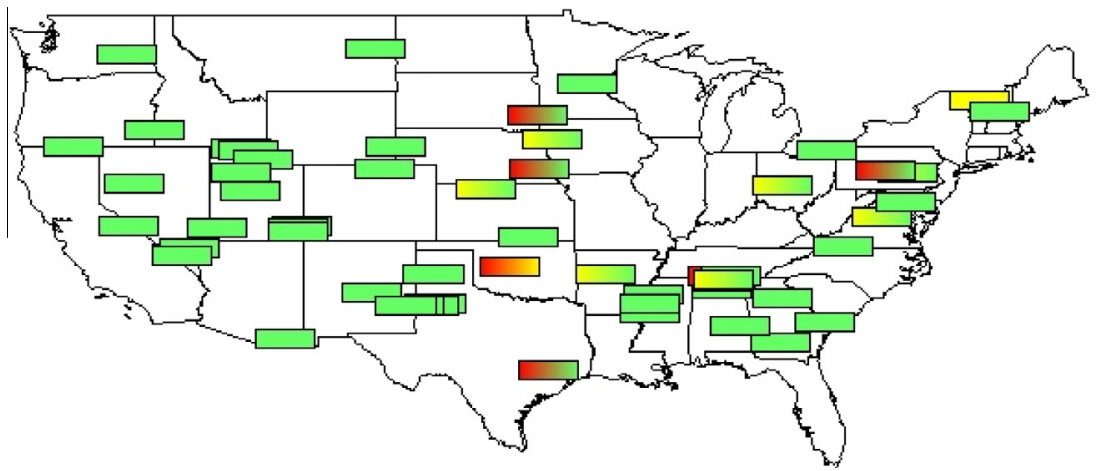

Fig. 14. SCAN calibration and validation results: right-end of bars reflect calibration performance, left-end reflects historical validation performance.

an extension of their soil moisture record using the calibrated models. Moreover, USCRN and SCAN locations that have missing soil moisture data due to malfunctioning sensors, but precipitation data remain available, can be filled via the estimates produced by a well-calibrated model.

As many in situ precipitation records are decades in length, generating a soil moisture record of comparable length is possible with numerous long-term analyses. Scientists interested in studying droughts for the purposes of prediction or remediation could benefit from extended soil moisture records at a variety of nationally-distributed test sites. Climate scientists attempting to understand climate change on a larger spatial and temporal scale will have access to the type of soil moisture record whose omission is among the many challenges facing the construction of more detailed GCMs requiring water balance estimates, of which soil moisture is an integral component (e.g. [4,17]. Finally in terms of agricultural decision-support and assessment, such widespread, longer-term soil moisture estimates could prove beneficial when compared with county-wide estimates of yield.

\section{Acknowledgements}

The U.S. Department of Agriculture (USDA) prohibits discrimination in all its programs and activities on the basis of race, color, national origin, age, disability, and where applicable, sex, marital status, familial status, parental status, religion, sexual orientation, genetic information, political beliefs, reprisal, or because all or part of an individual's income is derived from any public assistance program. (Not all prohibited bases apply to all programs.) Persons with disabilities who require alternative means for communication of program information (Braille, large print, audiotape, etc.) should contact USDA's TARGET Center at (202) 720-2600 (voice and TDD). To file a complaint of discrimination, write to USDA, Director,
Office of Civil Rights, 1400 Independence Avenue, S.W., Washington, D.C. 20250-9410, or call (800) 795-3272 (voice) or (202) 720-6382 (TDD). USDA is an equal opportunity provider and employer. This work was supported by NOAA through the Cooperative Institute for Climate and Satellites - North Carolina under Cooperative Agreement NA14NES432003. This work was also supported by the NASA Terrestrial Hydrology Program (NNH10ZDA001N-THP).

\section{Appendix A. CRN and SCAN sites not chosen}

Of the 114 CRN gauges, 91 were retained. This implies that 23 stations were excluded. Of these 23 omitted stations, their reasons for exclusion can be further specified as follows:

2 - Sites for which the CRN data were unavailable during validation (one in Louisiana, another in Oregon). Both of these models performed well in calibration, both silt loam soils.

9 - The Appalachians. These nine sites, in North Carolina (3), New York, Ohio, Pennsylvania, Tennessee, Virginia, and West Virginia all performed acceptably in calibration and collapsed duration validation. In 2013, when all of these models were validated, much wetter conditions were observed in this region. As such, the average soil moisture value increased by $0.08-0.10 \mathrm{~m}^{3} / \mathrm{m}^{3}$ and the calibrated models were no longer viable. All soils in this group are sandy loam, silt loam, or loam. Averages: $\rho=0.718$, RMSE $=0.072 \mathrm{~m}^{3} / \mathrm{m}^{3}$.

2 - Southeast. Two sites in South Carolina and Florida (both sandy soils) fail despite strong performance in calibration. Both, like those in the Appalachians experience far wetter conditions in validation. Averages: $\rho=0.805$, RMSE $=0.086 \mathrm{~m}^{3} / \mathrm{m}^{3}$.

2 - Too far north. For the sake of consistency, models were calibrated and validated between April and October to avoid risks of modeling periods of freezing/thawing. Two sites in Maine and 
Minnesota respectively failed not only in validation, but in calibration as well. It is likely that these sites featured frozen sensors during calibration and validation periods. Averages: $\rho=0.639$, RMSE $=0.074 \mathrm{~m}^{3} / \mathrm{m}^{3}$.

4 - Other complete failures. South Dakota, Kansas, Alabama, Missouri. These four sites also failed fairly significantly in calibration in addition to failure in validation. Soil types (silt loam, silty clay loam, and sandy loam) are similar, but also the among the most common soil textures found in over the 114 gauges. One potential explanation for the complete failure is flooded sensors, as values were reported at or above $0.5 \mathrm{~m}^{3} / \mathrm{m}^{3}$ at all four sites. Averages: $\rho=0.793$, RMSE $=0.079 \mathrm{~m}^{3} / \mathrm{m}^{3}$.

4 - Miscellaneous. Colorado, North Dakota, Missouri, Washington. In all four states, other models have performed well. Soil textures are silt loam, loam, or sandy loam. In all cases, the models were at least marginally-acceptable during calibration. In Colorado and Missouri, a wetter 2013 offers partial explanation. In Washington and North Dakota, perhaps freezing/thawing issues were an issue in 2013. Averages: $\rho=0.828$, RMSE $=0.076 \mathrm{~m}^{3} / \mathrm{m}^{3}$.

Of the 64 SCAN gauges for which sufficient data were available, 11 were excluded from consideration as a result of poor model performance. Reasons are specified below:

3 - Hawaii. Limited information is available about these sites. Soil texture data are unavailable, data ranges are widely disparate from year to year, performances in validation are far worse than any location examined in the continental U.S. Averages: $\rho=0.696$, RMSE $=0.104 \mathrm{~m}^{3} / \mathrm{m}^{3}$.

3 - Appalachians. Ohio, Pennsylvania, and Tennessee. Much like the CRN gauges, the wetter/dryer years damage the calibration/ validation procedure. Soil textures are silt loams or loam. These models are calibrated successfully, but fail in validation. Averages: $\rho=0.681$, RMSE $=0.067 \mathrm{~m}^{3} / \mathrm{m}^{3}$.

4 - Midwestern agricultural belt. Four sites in Nebraska, Oklahoma, South Dakota, and Texas almost seem to form a north-south line. Soil textures are sandy loams, silt loams, or silty clay loams. In many of these cases, more recent years were drier, challenging the backwards-looking models. Perhaps irrigation has been added near these sites in more recent years, causing models to be calibrated with a system that may not have been available previously. Averages: $\rho=0.711$, RMSE $=0.092 \mathrm{~m}^{3} / \mathrm{m}^{3}$.

1 - Utah. There are numerous SCAN sites in Utah, all but one of whom ultimately becomes a viable model. The sandy loam soil is typical of the region. This site appears to be a one-off problem in validation after a successful calibration. $\rho=0.622$, RMSE $=0.069 \mathrm{~m}^{3} / \mathrm{m}^{3}$.

\section{References}

[1] Bell JE, Palecki MA, Baker CB, Collins WG, Lawrimore JH, Leeper RD, et al. US climate reference network soil moisture and temperature observations. J Hydrometeorol 2013;14(3):977-88. http://dx.doi.org/10.1175/JHM-D-120146.1.

[2] Brocca L, Ciabatta L, Massari C, Moramarco T, Hahn S, Hasenauer S, et al. Soil as a natural rain gauge: estimating global rainfall from satellite soil moisture data. J Geophys Res Atmos 2014;119(9):5128-41. http://dx.doi.org/10.1002/ 2014JD021489.

[3] Brocca L, Zucco G, Moramarco T, Morbidelli R. Developing and testing a longterm soil moisture dataset at the catchment scale. J Hydrol 2013;490:144-51. http://dx.doi.org/10.1016/j.jhydrol.2013.03.029.

[4] Campoy A, Ducharne A, Cheruy F, Hourdin F, Polcher J, Dupont JC. Response of land surface fluxes and precipitation to different soil bottom hydrological conditions in a general circulation model. J Geophys Res D Atmos 2013;118(19):10725-39. http://dx.doi.org/10.1002/igrd.50627.
[5] Coopersmith EJ, Cosh MH, Petersen W, Prueger J, Niemeier JJ. Multi-scale soil moisture model calibration and validation: an ARS watershed on the south fork of the Iowa River. J Hydrometerol, in press. http://dx.doi.org/10.1175/ JHM-D-14-0145.1.

[6] Coopersmith EJ, Minsker BS, Wenzel CE, Gilmore BJ. Machine learning assessments of soil drying for agricultural planning. Comput Electron Agric 2014;104:93-104. http://dx.doi.org/10.1016/i.compag.2014.04.004.

[7] Coopersmith EJ, Minsker BS, Sivapalan M. Using similarity of soil texture and hydroclimate to enhance soil moisture estimation. Hydrol Earth Syst Sci 2014;18:3095-107. http://dx.doi.org/10.5194/hess-18-3095-2014.

[8] Diamond HJ, Karl TR, Palecki MA, Baker CB, Bell JE, Leeper RD, Easterling DR, et al. US climate reference network after one decade of operations: status and assessment. Bull Am Meteorol Soc 2013;94(4):485-98. http://dx.doi.org/ 10.1175/BAMS-D-12-00170.1.

[9] Dorigo WA, Xaver A, Vreugdenhil M, Gruber A, Hegyiová A, Sanchis-Dufau AD et al. Global automated quality control of in situ soil moisture data from the international soil moisture network. Vadose Zone J 2013;12:3. http:// dx.doi.org/10.2136/vzj2012.0097.

[10] Dunn SM, McDonnell JM, Vache KB. Factors influencing the residence time of catchment waters: a virtual experiment approach. Watet Resour Res 2007;43. http://dx.doi.org/10.1029/2006WR005393.

[11] Earl R. Prediction of trafficability and workability from soil moisture deficit. Soil Tillage Res 1997;40(3-4):155-68. http://dx.doi.org/10.1016/S01671987(96)01072-0.

[12] Entekhabi D, Rodriguez-Iturbe I. Analytical framework for the characterization of the space-time variability of soil moisture. Adv Water Resour 1994;17:35-45. http://dx.doi.org/10.1016/0309-1708(94)90022-1.

[13] Entekhabi D, Njoku EG, O'Neill PE, Kellogg K, Crow WT, Edelstein J, et al. The soil moisture active/passive mission (SMAP). Proc IEEE 2010;98(5):704-16. http://dx.doi.org/10.1109/IGARSS.2008.4779267.

[14] Farago T. Soil moisture content: statistical estimation of its probability distribution. J Clim Appl Meteorol 1985;24(4):371-6. http://dx.doi.org 10.1175/1520-0450(1985)024<0371:SMCSEO >2.0.CO;2.

[15] Goldberg DE. Genetic algorithms in search, optimization, and machine learning. Addison-Wesley Professional; 1989.

[16] Grayson RB, Western AW, Chiew FHS, Bloschl G. Preferred states in spatial soil moisture patterns: local and nonlocal controls. Watet Resour Res 1997;33(12):2897-908. http://dx.doi.org/10.1029/97WR02174.

[17] Joetzjer E, Douville H, Delire C, Ciais P. Present-day and future Amazonian precipitation in global climate models: CMIP5 versus CMIP3. Clim Dyn 2013;41(11-12):2921-36. http://dx.doi.org/10.1007/s00382-012-1644-1.

[18] Jones HG. Irrigation scheduling: advantages and pitfalls of plant-based methods. J Exp Bot 2004;55:2427-36. http://dx.doi.org/10.1093/jxb/erh213.

[19] Liu Q, Reichle RH, Bindlish R, Cosh MH, Crow WT, de Jeu R, et al. The contributions of precipitation and soil moisture observations to the skill of soil moisture estimates in a land data assimilation system. J Hydrometeorol 2011;12:750-65. http://dx.doi.org/10.1175/IHM-D-10-05000.1.

[20] Ochsner TE, Cosh MH, Cuenca RH, Dorigo WA, Draper CS, Hagimoto Y, et al State of the art in large-scale soil moisture monitoring. Soil Sci Soc Am J 2013;77:1888-919. http://dx.doi.org/10.2136/sssaj2013.03.0093.

[21] Pan F, Peters-Lidard CD, Sale MJ. An analytical method for predicting surface soil moisture from rainfall observations. Water Resour Res 2003;39(11). http://dx.doi.org/10.1029/2003WR002142.

[22] Pan F. Estimating daily surface soil moisture using a daily diagnostic soil moisture equation. J Irrig Drain Eng 2012;138(7):625-31. http://dx.doi.org/ 10.1061/(ASCE)IR.1943-4774.0000450.

[23] Rao NH, Sarma PBS, Chander S. Irrigation scheduling under a limited water supply. Agric Water Manag 1988;15:165-75. http://dx.doi.org/10.1016/03783774(88)90109-6.

[24] Saxton KE, Lenz AT. Antecedent retention indexes predict soil moisture. J Hydraul Div Proc Am Soc Civ Eng 1967:93:223-41.

[25] Schaefer GL, Cosh MH, Jackson TJ. The USDA natural resources conservation service soil climate analysis network (SCAN). J Atmos Oceanic Tech 2007;24:2073-7. http://dx.doi.org/10.1175/2007JTECHA930.1.

[26] Schulte RPO, Fealy R, Creamer RE, Towers W, Harty T, Jones RJA. A review of the role of excess soil moisture conditions in constraining farm practices under Atlantic conditions. Soil Use Manage 2012;;2012;(4):580-9. http://dx.doi.org 10.1111/i.1475-2743.2012.00437.x.

[27] Sheffield J, Goteti G, Wen F, Wood EF. A simulated soil moisture based drought analysis for the United States. J Geophys Res D Atmos 2004;109(24):1-19. http://dx.doi.org/10.1029/2004ID005182.

[28] Stillman S, Ninneman J, Zeng X, Franz T, Scott RL, Shuttleworth WJ, et al Summer soil moisture spatiotemporal variability in southeastern Arizona. J Hydrometeorol 2014;15:1473-85. http://dx.doi.org/10.1175//HM-D-13$\underline{0173.1 .}$. 